\title{
К АСПЕКТАМ ВЛИЯНИЯ ОЦЕНКИ ЭФФЕКТИВНОСТИ ДЕЯТЕЛЬНОСТИ ПРОФЕССОРСКО-ПРЕПОДАВАТЕЛЬСКОГО СОСТАВА ВЫСШЕГО УЧЕБНОГО ЗАВЕДЕНИЯ НА УКРЕПЛЕНИЕ ЭКОНОМИЧЕСКОЙ БЕЗОПАСНОСТИ РОССИЙСКОЙ ФЕДЕРАЦИИ
}

\author{
(c) 2019 Николаева Елена Анатольевна
}

кандидат социологических наук, доцент кафедры иностранных языков № 3 Российский экономический университет им. Г.В. Плеханова, Россия, Москва E-mail: yoltash82@mail.ru

\section{(c) 2019 Григорьева Ирина Васильевна}

кандидат филологических наук, доцент кафедры иностранных языков № 3 Российский экономический университет им. Г.В. Плеханова, Россия, Москва E-mail: i911g@mail.ru

\section{(c) 2019 Казимирова Ирина Сергеевна}

кандидат филологических наук, доцент кафедры иностранных языков № 3 Российский экономический университет им. Г.В. Плеханова, Россия, Москва E-mail: irinacasimirova@yandex.ru

\section{(c) 2019 Соколова Екатерина Иосифовна}

кандидат филологических наук, доцент кафедры иностранных языков № 3 Российский экономический университет им. Г.В. Плеханова, Россия, Москва E-mail:kafmkk@mail.ru

В статье авторов предпринята попытка рассмотрения влияния оценки эффективности деятельности профессорско-преподавательского состава высшего учебного заведения на укрепление экономической безопасности Российской Федерации. Объектом исследования выступил профессорско-преподавательский состав высших учебных заведений в Российской Федерации, а предметом - результаты оценки эффективности их деятельности. Теоретическое и методологическое значения исследования заключены в дополнении методической базы теории управления персоналом в части мульти аспектного представления анализируемой взаимосвязи в разрезе отдельных элементов. Практическое значение исследования связано с возможностью формирования направлений укрепления экономической безопасности в Российской Федерации за счет получения статистических данных в рамках анализируемой проблемы.

Ключевые слова: оценка, эффективность, влияние, высшее учебное заведение, экономика, безопасность, состав.

На современном этапе развития экономической системы Российской Федерации в условиях изменчивости внешних обстоятельств особый интерес в научной среде возникаем к коррелирующим объектам и процессам на микро и макроуровнях [5, с.116]. Так, например, за последнее время многие зарубежные специалисты в области управления персоналом $[7,8]$ собрали достаточную статистическую базу данных для исследования вопросов взаимной связи результатов оценки персонала в высшем профессиональном образовании и укрепления экономической безопасности в ретроспективе деятельности неко- торых стран [6, с.69; 8]. Результаты исследования выявили наличие значимой зависимости между анализируемыми процессами, что направило ученых на дальнейшее проведение их более глубокого анализа.

В Российской Федерации же, ввиду отсутствия необходимого объема статистически значимых данных [1, 2, 3], исследование обозначенных процессов [4, с.89] приобретает существенную актуальность и на данном этапе может быть инициировано с теоретической позиции с последующим дифференцированным углублением в практическую сторону вопроса. 
Ввиду этого, в рамках настоящего исследования авторами выделены и рассмотрены в теоретико-практической плоскости ряд аспектов влияния оценки эффективности деятельности профессорско-преподавательского состава высшего учебного заведения на укрепление экономической безопасности Российской Федерации.

Выделенные аспекты взаимного влияния анализируемых процессов в Российской Федерации приведены в таблице 1 .

По таблице 1 необходимо пояснить следующие моменты: выделено пять аспектов взаимного влияния эффективности деятельности профессорско-преподавательского состава высшего учебного заведения на укрепление экономической безопасности Российской Федерации: финансовые, экономические, социальные, информационные, нормативно-правовые; все указанные выше аспекты являются взаимосвязанными, но при этом могут быть рассмотрены, как самостоятельные предметы исследования в определенный период времени; периодами времени, рекомендуемыми для анализа взаимного влияния анализируемых процессов, являются: квартал, полугодие, год (анализ процессов на менее длительных интервалах времени, по мнению авторов, на данном этапе изученности проблемы не является целесообразным); изучение каждого процесса будет инициировано в рамках следующей последовательности: методологи- ческий блок, методический блок, практический блок и интеграционный блок; инструментарий проведения исследования анализируемых процессов является открытым (рекомендуемый акцент - нейросетевое моделирование результирующих показателей).

Детальное описание каждого из аспектов анализируемых процессов в Российской Федерации на начало 2019 года приведено в таблицах 2-6.

По итогам можно сделать вывод, что по состоянию на начало 2019 года в Российской Федерации вопросы взаимного влияния оценки эффективности деятельности профессорско-преподавательского состава высшего учебного заведения на укрепление экономической безопасности Российской Федерации является слабо изученными.

Для разрешения сложившейся ситуации планируется инициировать планомерное исследование анализируемых процессов в разрезе финансовых, экономических, социальных, информационных и нормативно-правовых аспектов.

Результаты исследования, по мере планомерного изучения анализируемого вопроса вопроса о взаимном влиянии процессов, проявятся в методологической, методической и практической плоскостях и могут быть использованы для широкого круга областей знания.

Таблица 1. Выделенные аспекты взаимного влияния оценки эффективности деятельности профессорско-преподавательского состава высшего учебного заведения на укрепление экономической безопасности Российской Федерации

\begin{tabular}{|c|c|c|}
\hline Наименование аспекта & Содержание аспекта & Примечание \\
\hline Финансовый & $\begin{array}{l}\text { - выявление взаимосвязей между } \\
\text { источниками финансирования } \\
\text { процессов; }\end{array}$ & $\begin{array}{l}\text { - методологический блок; } \\
\text { - методический блок; } \\
\text { - практический блок; } \\
\text { - интеграционный блок. }\end{array}$ \\
\hline Экономический & $\begin{array}{l}\text { - выявление взаимосвязей в } \\
\text { анализируемых процессах между } \\
\text { распределением и перераспреде- } \\
\text { лением ресурсов; }\end{array}$ & $\begin{array}{l}\text { - методологический блок; } \\
\text { - методический блок; } \\
\text { - практический блок; } \\
\text { - интеграционный блок. }\end{array}$ \\
\hline Социальный & $\begin{array}{l}\text { - выявлением взаимосвязей между } \\
\text { субъектами анализируемых про- } \\
\text { цессов; }\end{array}$ & $\begin{array}{l}\text { - методологический блок; } \\
\text { - методический блок; } \\
\text { - практический блок; } \\
\text { - интеграционный блок. }\end{array}$ \\
\hline Информационный & $\begin{array}{l}\text { - выявление взаимосвязей меж- } \\
\text { ду исходящими и нисходящими } \\
\text { потоками информации в анализи- } \\
\text { руемых процессах; }\end{array}$ & $\begin{array}{l}\text { - методологический блок; } \\
\text { - методический блок; } \\
\text { - практический блок; } \\
\text { - интеграционный блок. }\end{array}$ \\
\hline Нормативно-правовой & $\begin{array}{l}\text { - выявление взаимосвязей в } \\
\text { элементах нормативно-правовой } \\
\text { базы, регулирующих анализируе- } \\
\text { мые процессы. }\end{array}$ & $\begin{array}{l}\text { - методологический блок; } \\
\text { - методический блок; } \\
\text { - практический блок; } \\
\text { - интеграционный блок. }\end{array}$ \\
\hline
\end{tabular}


Таблица 2. Детальное описание финансового аспекта взаимного влияния анализируемых процессов в Российской Федерации по состоянию на начало 2019 года

\begin{tabular}{|l|l|l|}
\hline \multicolumn{1}{|c|}{$\begin{array}{c}\text { Ключевые элементы } \\
\text { аспекта }\end{array}$} & $\begin{array}{l}\text { Содержание ключевого } \\
\text { элемента }\end{array}$ & \multicolumn{1}{|c|}{ Пояснение содержания } \\
\hline Тип влияния & Прямой & $\begin{array}{l}\text { Содержание анализируемых процессов сопоставимо в } \\
\text { финансовой проекции }\end{array}$ \\
\hline $\begin{array}{l}\text { Преимущественный } \\
\text { приоритет влияния }\end{array}$ & Высокий & $\begin{array}{l}\text { Финансирование анализируемых процессов осущест- } \\
\text { вляется преимущественно из бюджетных источников }\end{array}$ \\
\hline $\begin{array}{l}\text { Превалирующий } \\
\text { взаимосвязей }\end{array}$ & $\begin{array}{l}\text { Корреляционное взаи- } \\
\text { модействие анализируе- } \\
\text { мых показателей }\end{array}$ & $\begin{array}{l}\text { При наличии необходимого набора статистически } \\
\text { значимых данных }\end{array}$ \\
\hline $\begin{array}{l}\text { Необходимость эмулиро- } \\
\text { вания данных }\end{array}$ & Средняя & $\begin{array}{l}\text { Большая часть данных, необходимых для сопоставле- } \\
\text { ния анализируемых процессов в финансовой плоско- } \\
\text { сти является доступной }\end{array}$ \\
\hline $\begin{array}{l}\text { Планируемый период } \\
\text { получения информации }\end{array}$ & Два календарных года & $\begin{array}{l}\text { Набор статистически значимых данных, характеризу- } \\
\text { ющих анализируемые процессы в финансовой плоско- } \\
\text { сти за последние 10 лет, планируется осуществить в } \\
\text { период до конца 2020 года }\end{array}$ \\
\hline
\end{tabular}

Таблица 3. Детальное описание экономического аспекта взаимного влияния анализируемых процессов в Российской Федерации по состоянию на начало 2019 года

\begin{tabular}{|l|l|l|}
\hline \multicolumn{1}{|c|}{$\begin{array}{l}\text { Ключевые элементы } \\
\text { аспекта }\end{array}$} & $\begin{array}{c}\text { Содержание ключевого } \\
\text { элемента }\end{array}$ & \multicolumn{1}{|c|}{ Пояснение содержания } \\
\hline Тип влияния & Прямой & $\begin{array}{l}\text { Содержание анализируемых процессов сопоставимо в } \\
\text { экономической проекции }\end{array}$ \\
\hline $\begin{array}{l}\text { Преимущественный } \\
\text { приоритет влияния }\end{array}$ & $\begin{array}{l}\text { Экономическая составляющая анализируемых процес- } \\
\text { сов имеет зачастую тождественную природу }\end{array}$ \\
\hline $\begin{array}{l}\text { Превалирующий меха- } \\
\text { низм поиска взаимос- } \\
\text { вязей }\end{array}$ & $\begin{array}{l}\text { Корреляционное взаимо- } \\
\text { действие анализируемых } \\
\text { показателей / эксперт- } \\
\text { ный анализ }\end{array}$ & $\begin{array}{l}\text { При наличии необходимого набора статистически } \\
\text { значимых данных }\end{array}$ \\
\hline $\begin{array}{l}\text { Необходимость эмулиро- } \\
\text { вания данных }\end{array}$ & $\begin{array}{l}\text { Большая часть данных, необходимых для сопостав- } \\
\text { ления анализируемых процессов в экономической } \\
\text { плоскости является доступной }\end{array}$ \\
\hline $\begin{array}{l}\text { Планируемый период } \\
\text { получения информации }\end{array}$ & $\begin{array}{l}\text { Два календарных года } \\
\text { Ющих статистически значимых данных, характеризу- } \\
\text { скости за последние 10 лет, планируется осуществить в } \\
\text { период до конца 2020 года }\end{array}$ \\
\hline
\end{tabular}

Таблица 4. Детальное описание социального аспекта взаимного влияния анализируемых процессов в Российской Федерации по состоянию на начало 2019 года

\begin{tabular}{|c|c|c|}
\hline $\begin{array}{l}\text { Ключевые элементы } \\
\text { аспекта }\end{array}$ & $\begin{array}{l}\text { Содержание ключевого } \\
\text { элемента }\end{array}$ & Пояснение содержания \\
\hline Тип влияния & Косвенный & $\begin{array}{l}\text { Содержание анализируемых процессов условно сопо- } \\
\text { ставимо в социальной проекции }\end{array}$ \\
\hline $\begin{array}{l}\text { Преимущественный } \\
\text { приоритет влияния }\end{array}$ & Средний & $\begin{array}{l}\text { Социальная составляющая анализируемых процессов } \\
\text { значительно различается }\end{array}$ \\
\hline $\begin{array}{l}\text { Превалирующий меха- } \\
\text { низм поиска взаимос- } \\
\text { вязей }\end{array}$ & $\begin{array}{l}\text { Корреляционное взаимо- } \\
\text { действие анализируемых } \\
\text { показателей / логические } \\
\text { взаимосвязи / эксперт- } \\
\text { ный анализ }\end{array}$ & $\begin{array}{l}\text { Статистически значимый набор данных не позволяет } \\
\text { провести полноценный поиск взаимосвязей анализи- } \\
\text { руемых показателей }\end{array}$ \\
\hline $\begin{array}{l}\text { Необходимость эмулиро- } \\
\text { вания данных }\end{array}$ & Относительно высокая & $\begin{array}{l}\text { Лишь некоторая часть данных, необходимых для со- } \\
\text { поставления анализируемых процессов в социальной } \\
\text { плоскости является доступной }\end{array}$ \\
\hline $\begin{array}{l}\text { Планируемый период } \\
\text { получения информации }\end{array}$ & Три календарных года & $\begin{array}{l}\text { Набор статистически значимых данных, характеризу- } \\
\text { ющих анализируемые процессы в социальной плоск-- } \\
\text { сти за последние } 10 \text { лет, планируется осуществить в } \\
\text { период до конца } 2021 \text { года }\end{array}$ \\
\hline
\end{tabular}


Таблица 5. Детальное описание информационного аспекта взаимного влияния анализируемых процессов в Российской Федерации по состоянию на начало 2019 года

\begin{tabular}{|c|c|c|}
\hline $\begin{array}{l}\text { Ключевые элементы } \\
\text { аспекта }\end{array}$ & $\begin{array}{l}\text { Содержание ключевого } \\
\text { элемента }\end{array}$ & $\begin{array}{l}\text { Пояснение } \\
\text { содержания }\end{array}$ \\
\hline Тип влияния & Косвенный & $\begin{array}{l}\text { Содержание анализируемых процессов условно сопо- } \\
\text { ставимо в информационной проекции }\end{array}$ \\
\hline $\begin{array}{l}\text { Преимущественный } \\
\text { приоритет влияния }\end{array}$ & Низкий & $\begin{array}{l}\text { Информационная составляющая анализируемых про- } \\
\text { цессов существенно различается }\end{array}$ \\
\hline $\begin{array}{l}\text { Превалирующий меха- } \\
\text { низм поиска взаимос- } \\
\text { вязей }\end{array}$ & $\begin{array}{l}\text { Корреляционное взаимо- } \\
\text { действие анализируемых } \\
\text { показателей / логические } \\
\text { взаимосвязи / эвристи- } \\
\text { ческий анализ / эксперт- } \\
\text { ный анализ } \\
\end{array}$ & $\begin{array}{l}\text { Анализ процессов здесь не может быть проведен лишь } \\
\text { по статистически значимым данным }\end{array}$ \\
\hline $\begin{array}{l}\text { Необходимость эмулиро- } \\
\text { вания данных }\end{array}$ & Высокая & $\begin{array}{l}\text { Сбор статистически значимых данных здесь суще- } \\
\text { ственно затруднен }\end{array}$ \\
\hline $\begin{array}{l}\text { Планируемый период } \\
\text { получения информации }\end{array}$ & Три календарных года & $\begin{array}{l}\text { Набор информации и сведений, характеризующих } \\
\text { анализируемые процессы в информационной плоско- } \\
\text { сти за последние } 10 \text { лет, планируется осуществить в } \\
\text { период до конца } 2021 \text { года }\end{array}$ \\
\hline
\end{tabular}

Таблица 6. Детальное описание информационного аспекта взаимного влияния анализируемых процессов в Российской Федерации по состоянию на начало 2019 года

\begin{tabular}{|c|c|c|}
\hline $\begin{array}{l}\text { Ключевые элементы } \\
\text { аспекта }\end{array}$ & $\begin{array}{l}\text { Содержание ключевого } \\
\text { элемента }\end{array}$ & $\begin{array}{l}\text { Пояснение } \\
\text { содержания }\end{array}$ \\
\hline Тип влияния & Нейтральный & $\begin{array}{l}\text { Содержание анализируемых процессов слабо сопоста- } \\
\text { вимо в нормативно-правовой плоскости }\end{array}$ \\
\hline $\begin{array}{l}\text { Преимущественный } \\
\text { приоритет влияния }\end{array}$ & Низкий & $\begin{array}{l}\text { Нормативно-правовые составляющие анализируемых } \\
\text { процессов различаются весьма существенно }\end{array}$ \\
\hline $\begin{array}{l}\text { Превалирующий меха- } \\
\text { низм поиска взаимос- } \\
\text { вязей }\end{array}$ & $\begin{array}{l}\text { Логические взаимосвязи } \\
\text { / эвристический анализ / } \\
\text { экспертный анализ }\end{array}$ & $\begin{array}{l}\text { Анализ процессов здесь может быть проведен лишь на } \\
\text { основе косвенных данных }\end{array}$ \\
\hline $\begin{array}{l}\text { Необходимость эмулиро- } \\
\text { вания данных }\end{array}$ & Высокая & $\begin{array}{l}\text { Практически все необходимые данные здесь требуют } \\
\text { значительного эмулирования }\end{array}$ \\
\hline $\begin{array}{l}\text { Планируемый период } \\
\text { получения информации }\end{array}$ & Третий квартал 2019 года & $\begin{array}{l}\text { Ввиду существенной потери актуальности содержания } \\
\text { нормативно-правовых положений период ограничен } \\
\text { тремя кварталами }\end{array}$ \\
\hline
\end{tabular}

\section{Библиографический список}

1. Бигжанова А. М., Безверхая О.Н. Угрозы экономической безопасности национальной экономики России: проявления, нейтрализация / А.М. Бигжанова, О.Н. Безверхая // Молодой ученый - Казань: Изд-во «Молодой учёный» - 2018. - № 13.- С. 221-225.

2. Грандонян К.А. Экономическая безопасность и гражданское общество в России в контексте цифровизации экономики / К.А. Грандонян // Экономическая безопасность и качество - Саратов: Изд-во Саратовский социально-экономический институт (филиал) РЭУ им. Г.В. Плеханова - 2018. - № 1.- С. 87-91.

3. Низдиминов М. Н., Пыжов, А. М., Тинькова Е.В. Подходы к оценке и измерению эффективности мотивации и адаптации персонала / М.Н. Низдиминов, А. М. Пыжов, Е.В. Тинькова // Дельта науки - Воронеж: Изд-во Общество с ограниченной ответственностью «АгроТехХолдинг» - 2017. - № 1.- С. 33-37.

4. Николаева Е. А. и другие Инструменты реализации стратегических инициатив высшего учебного заведения в целях повышения качества образовательного процесса / Е.А. Николаева и другие // Экономические науки - Москва: Изд-во ООО «24-Принт» - 2018. - № 9.- С. 87-90.

5. Халимендик В.Б. Формы взаимодействия научных организаций, вузов и промышленных предприятий / В.Б. Халимендик // Экономические науки - Москва: Изд-во ООО «24-Принт», 2013. - № 7._ С. 115-120. 
6. Russell, J.S. and Goode, D.L. (1988), “An analysis of managers' reactions to their own performance appraisal feedback”, Journal of Applied Psychology, Vol. 73, pp. 63-77.

7. Menggang, Li (2013). Research on Industrial Security Theory Springer Heidelberg. New York p. 442.

8. Компания E\&Y [Электронный ресурс]: аналитические материалы - Официальный сайт компании «Ernst \& Young», 2019.- Режим доступа: https://www.ey.com 